Article

\title{
Effects of Short-Range Order on the Magnetic and Mechanical Properties of FeCoNi(AlSi) $x$ High Entropy Alloys
}

\author{
Wenqiang Feng ${ }^{1,2,3, *} \mathbb{C}^{\mathbb{D}}$, Yang $\mathrm{Qi}^{4}$ and Shaoqing Wang ${ }^{1}$ \\ 1 Shenyang National Laboratory for Materials Science, Institute of Metal Research, Chinese Academy of Sciences, \\ Shenyang 110016, China; sqwang@imr.ac.cn \\ 2 College of Science, University of Science and Technology Liaoning, Anshan 114051, China \\ 3 University of Chinese Academy of Sciences, Beijing 100049, China \\ 4 College of Science, Northeastern University, Shenyang 110819, China; qiyang@imp.neu.edu.cn \\ * Correspondence: wqfeng14b@imr.ac.cn; Tel.: +86-024-2397-1846
}

Received: 19 September 2017; Accepted: 2 November 2017; Published: 6 November 2017

\begin{abstract}
The properties of a material are sensitive to chemically-ordered structure in multi-element alloys. Understanding the effects of chemical short-range order (SRO) on magnetic and mechanical properties is important. In this work, we use the Monte Carlo method in combination with density functional theory to investigate atomic nearest neighbor distribution, magnetic moment and elastic modulus in $\mathrm{FeCoNi}(\mathrm{AlSi})_{\mathrm{x}}$ alloys. It is found that the prominent feature of the $\mathrm{FeCoNi}(\mathrm{AlSi})_{\mathrm{x}}$ alloys is the change of SRO parameters: the SRO parameters are positive between $\mathrm{Al}-\mathrm{Al}, \mathrm{Al}-\mathrm{Si}$, Si-Si pairs and negative between $\mathrm{Ni}-\mathrm{Al}, \mathrm{Co}-\mathrm{Si}, \mathrm{Fe}-\mathrm{Co}, \mathrm{Ni}-\mathrm{Si}$ and $\mathrm{Fe}-\mathrm{Si}$ pairs. The $\mathrm{Al}$ and $\mathrm{Si}$ elements tend to bond with $\mathrm{Fe}, \mathrm{Co}$, Ni elements to form an $\mathrm{SRO}$ structure. The change of the atomic nearest neighbor environment leads to a reduction in the atomic magnetic moments of magnetic elements. The calculated saturation magnetizations by considering the effect of SRO are in good accord with the experimental values. We further show that SRO leads to an increase of the elastic modulus, by sacrificing ductility and isotropy. In the study of the structure and properties of high entropy alloys, the effect of SRO should not be ignored.
\end{abstract}

Keywords: high entropy alloys; short-range order; Monte Carlo simulation; density functional theory

\section{Introduction}

In recent years, there have been extensive experimental investigations of multi-component alloys after the new alloy design concept, high entropy alloys (HEAs), was proposed [1,2]. HEAs consist of at least five principal elements, each element with a $5-35 \%$ concentration. These alloys have many exceptional properties compared with the traditional alloys due to the high mixing entropy, sluggish diffusion and lattice distortion effects, including good thermal stability, high mechanical strength and excellent corrosion resistance [3-5]. The properties of HEAs, such as hardness, ductility and magnetic properties can be tuned by changing the type and concentration of components [6-8]. These novel properties of HEAs have potential applications in refractory materials, wear-resistant materials and magnetic materials.

In general, HEAs are considered to be random solid solutions (RSS), and all constituent atoms randomly distribute on the available lattice sites. But is this really true? In fact, the diversity in atomic radii and the different attractive interactions between the constituent elements will result in a short-range ordered structure [9]. The SRO structures have been found in many engineering materials such as $\mathrm{FeV}, \mathrm{FeAl}$ and $\mathrm{FeCr}$ alloys [10-12]. It will significantly affect the structural stability, magnetic and mechanical properties. The presence of SRO in these binary alloys suggests that some 
ordered structures may also exist in HEAs. Manzoni et al. reported that there is an Al-Ni rich region in AlCoCrFeNi alloy [13]. Zuo et al. found that there are Fe-Co and Al-Ni-Si rich phases in $\mathrm{FeCoNi}(\mathrm{AlSi})_{0.2}$ alloy [14]. Zhang et al. provided the experimental evidence of SRO in $\mathrm{NiCoCr}$ alloy [15]. Their work showed that $\mathrm{Cr}$ atoms separate from each other, but bond with $\mathrm{Ni}$ and $\mathrm{Co}$ atoms to form SRO structures. The SRO will decrease the configurational entropy and change the free energy of high entropy alloys [16]. It is very important to study the formation of SRO structure and investigate the effects of SRO on the properties of HEAs. However, the study of SRO is relatively scarce in high entropy alloys [17], which is due to the difficulty of probing SRO behavior by conventional X-ray scattering or neutron diffraction, and due to the complex analysis of experimental data. Reverse Monte Carlo (RMC) modelling [18] is a useful method to fit atomic scale structure by inverting experimental diffraction data, using which researchers can further understand the relationship between local atomic structure and material properties. Kaban et al. studied $\mathrm{Co}_{43} \mathrm{Fe}_{20} \mathrm{Ta}_{5.5} \mathrm{~B}_{31.5}$ metallic glass with RMC by resolving ten partial pair distribution functions (PDF) to determine the SRO [19]. However, with the increase of constituent elements, it becomes more difficult to resolve the partial distribution function and calculate the total structural factor, which limits its application in HEAs.

First-principles calculation based on density functional theory (DFT) is a powerful tool to explore the structure and properties of materials [20,21]. By constructing appropriate atomic structures, researchers can study the structural stability and alloy properties. Recently, some hybrid Monte Carlo (MC) methods in combination with density functional theory calculation were performed to study SRO behavior in high entropy alloys $[9,16]$. Widom et al. studied refractory metal Mo-Nb-Ta-W with hybrid Monte Carlo/molecular dynamics method. The simulation result showed that a cesium-chloride ordered structure emerge between the mixed $(\mathrm{Mo}, \mathrm{W})$ sites and the mixed $(\mathrm{Nb}, \mathrm{Ta})$ sites. Tamm et al. investigated the SRO behavior in $\mathrm{NiCrCo}$ and $\mathrm{NiCrCoFe}$ alloys and found obvious short-range order between $\mathrm{Ni}-\mathrm{Cr}$, $\mathrm{Cr}-\mathrm{Co}$ and Ni-Fe pairs. Compared to the classical Monte Carlo method combined with empirical interaction potentials, the first-principles calculation can obtain more accurate potential energy and the Monte Carlo swaps of different atomic species, allowing researchers to probe the SRO in high entropy alloys. The hybrid method makes the atomic structure evolve toward the global energy minimum in the simulation. These results demonstrated that the hybrid method is suitable for the study of SRO in HEAs.

Recently, some FeCoNi-based high entropy alloys with attractive soft magnetic properties have been obtained [22-24]. In the $\mathrm{FeCoNi}(\mathrm{AlSi})_{\mathrm{x}}$ ( $\mathrm{x}$ is in the molar ratio of $\mathrm{Al}$ and $\mathrm{Si}$ elements) alloys, by adding $\mathrm{Al}$ and $\mathrm{Si}$ elements into $\mathrm{FeCoNi}$ alloy, researchers can adjust lattice distortion and increase electrical resistivity, thus forming appealing soft magnetic alloys. However, $\mathrm{Al}$ and $\mathrm{Si}$ elements have strong attractive interactions with $\mathrm{Fe}, \mathrm{Co}$ and $\mathrm{Ni}$ elements, which can be seen from the more negative binary mixing enthalpies of $\mathrm{Ni}-\mathrm{Si}, \mathrm{Co}-\mathrm{Si}$ and $\mathrm{Ni}-\mathrm{Al}$ pairs with $-40,-38$ and $-22 \mathrm{~kJ} / \mathrm{mol}$, respectively. $\mathrm{Al}$ and $\mathrm{Si}$ atoms prefer to be surrounded by $\mathrm{Fe}, \mathrm{Co}$ and $\mathrm{Ni}$ atoms to reduce the potential energy, which will lead to the formation of an SRO structure. In this work, we investigate the SRO behavior of $\mathrm{FeCoNi}(\mathrm{AlSi})_{\mathrm{x}}$ alloys by using the MC method combined with density functional theory calculation. The MC method is carried out to search for the lower energy structure, and density functional theory is used for structure relaxation and the calculation of system energy. We calculate the formation enthalpies, SRO parameters, magnetic moments, and elastic moduli of both initial structures and the structures with SRO. It is expected that the present work can deepen the understanding of SRO behavior in high entropy alloys.

\section{Methodology}

The two competitive structures for FeCoNi(AlSi) $)_{x}$ alloys are the face centered cubic $(\mathrm{FCC})$ phase and body centered cubic (BCC) phase. The FCC and BCC supercell structures of FeCoNi(AlSi) alloys $(\mathrm{x}=0,0.1,0.2,0.4,0.5$ and 0.8$)$ were built according to the maximum entropy (MaxEnt) method. Details of the MaxEnt method can be found in References [25-27]. The supercell structures consist of 108 atoms for the FCC phase and 128 atoms for the BCC phase. For comparison, the 92-atom FCC 
and $\mathrm{BCC}$ special quasi-random structures (SQS) of FeCoNi(AlSi) $)_{0.8}$ alloy were generated by using the mcsqs code with the Alloy-Theoretic Automated Toolkit (ATAT) package [28].

The structure relaxation and energy calculation were performed using DFT implemented with the Vienna Ab-Initio Simulation Package (VASP, University of Vienna, version: 5.4.1.05, Vienna, Austria) [21]. The exchange-correlation functional was treated within the generalized gradient approximation as described by Perdew-Burke-Ernzerhof (PBE) [29]. Energy cutoffs for the plane wave in all calculations were set to $300 \mathrm{eV}$. The reciprocal space energy integration was performed by the Monkhorst-Pack technique with $2 \times 2 \times 2$ mesh. The self-consistence convergence criterion for electron iterations was set to $10^{-5} \mathrm{eV}$ per atom. The valence electrons of $\mathrm{Fe}, \mathrm{Co}, \mathrm{Ni}, \mathrm{Al}$ and $\mathrm{Si}$ atoms were eight, nine, 10, three and four, respectively. From Wikipedia, we know that the Curie temperature of $\mathrm{Fe}, \mathrm{Co}$ and $\mathrm{Ni}$ are 1043, 1388 and $628 \mathrm{~K}$. Körmann et al. predicted the Curie temperature of FeCoNi is $868 \mathrm{~K}$ [30]. The Curie temperature of $\mathrm{Co}_{2} \mathrm{FeSi}$ and $\mathrm{Co}_{2} \mathrm{FeAl}$ are all above $1000 \mathrm{~K}$. Dobrzynski et al. reported that the Curie temperature of $\mathrm{Fe}_{2.94} \mathrm{Al}_{0.38} \mathrm{Si}_{0.68}$ is $794 \mathrm{~K}$ [31]. There is not any Curie temperature of $\mathrm{FeCoNi}(\mathrm{AlSi})_{\mathrm{X}}$ alloys reported. However, Zhang et al. showed that the saturation magnetizations of $\mathrm{FeCoNi}(\mathrm{AlSi})_{\mathrm{x}}$ alloys range from 1.32 to $0.46 \mathrm{~T}(\mathrm{x}=0$ to 0.8$)$ [22]. We predict that the Curie temperature of FeCoNi (AlSi)x alloy is above $300 \mathrm{~K}$. Thus, the magnetic state must be considered. All the calculations done were spin-polarized, with the magnetic moments of $\mathrm{Fe}, \mathrm{Co}$ and $\mathrm{Ni}$ atoms initialized with 3, 2 -and $1 \mu_{\mathrm{B}}$, respectively. The calculations in this work did not include the orbital magnetic moment.

In order to probe $\mathrm{SRO}$ in $\mathrm{FeCoNi}(\mathrm{AlSi})_{\mathrm{x}}$ alloys, the Monte Carlo method was carried out in the simulation. The generation of a new atomic configuration is a two-step process. Firstly, the potential energy with the current atomic structure was calculated. In the next step, two different kinds of constituent atoms were selected and the potential energy after the swap of their positions was calculated. The position swap is based on the Metropolis-Hastings sampling [32] with the acceptance probability $p=\exp (-\beta \Delta E) ; \Delta E$ is the energy difference between swapped and not-swapped structures, $\beta=\mathrm{k}_{B} T, T=300 \mathrm{~K}$. The FeCoNi (FCC), FeCoNi(AlSi) $)_{0.2}(\mathrm{FCC}), \mathrm{FeCoNi}(\mathrm{AlSi})_{0.4}$ $(\mathrm{BCC})$ and $\mathrm{FeCoNi}(\mathrm{AlSi})_{0.8}(\mathrm{BCC})$ structures generated by the MaxEnt method, and FeCoNi(AlSi $)_{0.8}$ (BCC) generated by the mcsqs method, were selected as the initial starting point in the MC simulations. Each MC simulation ran for 3000 MC steps. The structure relaxations and energy calculations for the final structures with SRO and the initial structures were fully conducted with a higher number of k-points $(3 \times 3 \times 3)$ to increase accuracy.

The Warren-Cowley SRO parameter $\alpha_{i j}$ [33] was used to described the degree of short-range order in the FeCoNi(AlSi) $)_{x}$ alloys. The nearest neighbor SRO parameter $\alpha_{i j}$ can be calculated by Equation (1), where $c_{j}$ is the molar fraction of the type $j$ element and $p_{i j}$ is the probability of finding the type $j$ element around the type $i$ element in the nearest neighbor shell. The SRO parameter vanishes if $p_{i j}=c_{j}$, meaning that there is no site preference between the type $i$ and type $j$ element. The negative $\alpha_{i j}$ indicates the increase in the number of $i$ and $j$ pairs, while the positive value corresponds to the opposite.

$$
\alpha_{i j}=1-\frac{p_{i j}}{c_{j}}
$$

Formation enthalpy $E_{f}$ is defined in Equation (2), where $E_{\text {tot }}$ is the zero-temperature total energy per atom, $c_{i}$ is the molar fraction of the type $i$ element. $E_{i}^{\text {ref }}$ is the ground state energy of type $i$ element in its stable phase and is calculated by using the same DFT code and pseudopotential.

$$
E_{\mathrm{f}}=E_{\mathrm{tot}}-\sum_{\mathrm{i}}^{\mathrm{n}} \mathrm{c}_{\mathrm{i}} E_{\mathrm{i}}^{\mathrm{ref}}
$$




\section{Results and Discussion}

\subsection{Single-Phase High Entropy Alloy (HEA) Stability}

It was reported that non-equimolar FeCoNi(AlSi) $)_{\mathrm{x}}$ alloys form the FCC phase for $0 \leq \mathrm{x} \leq 0.2$ and the BCC phase for $0.4 \leq \mathrm{x} \leq 0.8$ [22]. In Figure 1, we present the MaxEnt structures of FeCoNi $(\mathrm{AlSi})_{\mathrm{x}}$ for $\mathrm{x}=0.2(\mathrm{FCC}), \mathrm{x}=0.4(\mathrm{BCC})$ and $\mathrm{x}=0.8(\mathrm{BCC})$ and SQS structure with $\mathrm{x}=0.8(\mathrm{BCC})$ in their ideal, unrelaxed forms. We performed the structure relaxation and total energy calculation by using the settings described in Section 2. Table 1 shows the lattice parameters, formation enthalpies $\mathrm{E}_{f}$ with BCC and FCC structures and the energy difference between the BCC and FCC phases $\Delta E_{t}, \Delta E_{t} \equiv E_{f}^{B C C}-E_{f}^{F C C}$. The positive $\Delta E_{t}$ indicates that the FCC structure is more stable, and the negative $\Delta E_{t}$ shows that the BCC structure is more stable. As shown in Table 1, when the fraction of $\mathrm{Al}$ and $\mathrm{Si}$ elements is smaller $(\mathrm{x} \leq 0.2)$, the energy difference $\Delta E_{t}$ is positive, indicating that the FCC structure is more stable. When the fraction of $\mathrm{Al}$ and Si elements is larger $(\mathrm{x} \geq 0.4)$, the energy difference $\Delta E_{t}$ is negative, demonstrating that the BCC structure is more stable. The experimental lattice parameters are $a=3.571 \AA$ for $\mathrm{x}=0$ [34] and $a=3.594 \AA$ for $\mathrm{x}=0.2$ [14]. The calculated results are $a=3.545 \AA(\mathrm{x}=0)$ and $a=3.554 \AA(\mathrm{x}=0.2)$. When $\mathrm{x}=0.8$, there is no experimental lattice parameter available, however, the calculated lattice parameter $a=2.853 \AA$ with the MaxEnt structure and $a=2.874 \AA$ with the SQS structure were obtained. The consistency of the calculated and experimental values validates the MaxEnt models employed.

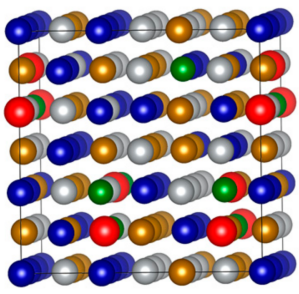

(a)

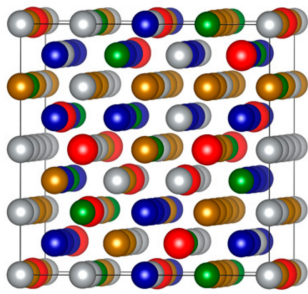

(b)

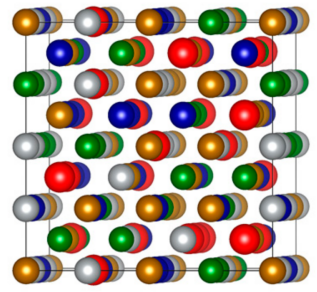

(c)

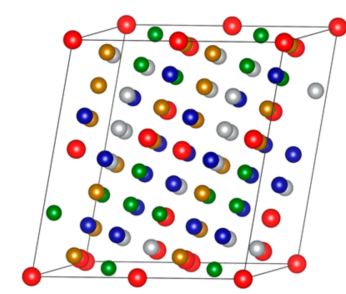

(d)

Figure 1. Crystal structures of the MaxEnt structures and special quasi-random structures (SQS) structure in their ideal, unrelaxed forms: (a) MaxEnt-108 for $\mathrm{x}=0.2$; (b) MaxEnt-128 for $\mathrm{x}=0.4$; (c) MaxEnt-128 for $\mathrm{x}=0.8$; (d) SQS-92 for $\mathrm{x}=0.8$.

Table 1. Calculated lattice parameters (a), formation enthalpies and the energy differences between face-centered cubic (FCC) phase and body-centered cubic (BCC) phases as a function of $\mathrm{Al}$ and $\mathrm{Si}$ fraction $\mathrm{x}$.

\begin{tabular}{ccccccc}
\hline Alloy & Structure & $\boldsymbol{a} \mathbf{( F C C )}(\AA)$ & $\boldsymbol{a}(\mathrm{BCC})(\AA)$ & $\boldsymbol{E}_{f}^{B C C}(\mathbf{e V / a t o m})$ & $\boldsymbol{E}_{f}^{F C C}(\mathbf{e V / a t o m})$ & $\Delta \boldsymbol{E}_{\boldsymbol{t}}(\mathbf{e V} / \mathbf{a t o m})$ \\
\hline $\mathrm{FeCoNi}$ & MaxEnt & 3.545 & 2.821 & 0.015 & -0.027 & 0.042 \\
$\mathrm{FeCoNi}(\mathrm{AlSi})_{0.1}$ & MaxEnt & 3.547 & 2.826 & -0.047 & -0.067 & 0.020 \\
$\mathrm{FeCoNi}(\mathrm{AlSi})_{0.2}$ & MaxEnt & 3.554 & 2.832 & -0.132 & -0.145 & -0.012 \\
$\mathrm{FeCoNi}(\mathrm{AlSi})_{0.4}$ & MaxEnt & 3.561 & 2.836 & -0.209 & -0.191 & -0.018 \\
$\mathrm{FeCoNi}(\mathrm{AlSi})_{0.5}$ & MaxEnt & 3.569 & 2.838 & -0.240 & -0.219 & -0.021 \\
$\mathrm{FeCoNi}(\mathrm{AlSi})_{0.8}$ & MaxEnt & 3.581 & 2.853 & -0.325 & -0.296 & -0.029 \\
$\mathrm{FeCoNi}(\mathrm{AlSi})_{0.8}$ & SQS & 3.598 & 2.874 & -0.298 & -0.265 & -0.033 \\
\hline
\end{tabular}

\subsection{Short-Range Order (SRO) in FeCoNi(AlSi) $)_{x}$ Alloys}

The evolution of the relative potential energy and SRO parameters of FeCoNi (AlSi) $)_{0.8}$ alloy are shown in Figure 2. The relative potential energy is defined as the energy difference between the potential energy of the ith MC step and the initial potential energy. In the case that the 92-atom SQS structure is selected as the initial starting structure, all the constituent atoms are randomly distributed in the lattice positions, $\alpha_{i i}=0$ and $\alpha_{i j}=0$ (Figure $2 \mathrm{a}, \mathrm{b}$ ). Figure $2 \mathrm{~b}$ shows that there are major deviations of SRO parameters between the finial structure and the SQS structure. The average numbers 
of $\mathrm{Al}-\mathrm{Al}$ and $\mathrm{Si}-\mathrm{Si}$ pairs are reduced by $\sim 80 \%$, the nearest neighbor number changes from 2.1 for the random case to about 0.5 for the SRO case, and the average number of Al-Si pairs is reduced by $\sim 50 \%$, indicating $\mathrm{Al}$ (or $\mathrm{Si}$ ) atoms separate from each other. Meanwhile, it can be seen that there is rapid growth of the average number of $\mathrm{Ni}-\mathrm{Al}$ pairs, followed by $\mathrm{Co}-\mathrm{Si}, \mathrm{Co}-\mathrm{Al}$ and Ni-Si pairs. The rapid growth of $\mathrm{Ni}-\mathrm{Al}$ pairs shows that the $\mathrm{Ni}-\mathrm{Al}$ pair first formed during the solidification from the liquid phase. The Ni-Al pairs will form a B2-orderd parent crystal structure, which is an ordered structure based on BCC with Pearson symbol of cP2. Si element also have negative mixing enthalpies with Ni, Co and Fe elements, the binary mixing enthalpies of Ni-Si, Co-Si and Fe-Si pairs are $-40,-38$ and $-35 \mathrm{~kJ} / \mathrm{mol}$, respectively. Si atoms prefer to separate with $\mathrm{Al}$ and $\mathrm{Si}$ atoms, and bond with $\mathrm{Ni}, \mathrm{Co}$ and Fe atoms. Raja et al. studied the structural properties of $\mathrm{Fe}_{3-\mathrm{x}} \mathrm{Co}_{\mathrm{x}} \mathrm{Si}$ alloys $(0 \leq \mathrm{x} \leq 1)$ using $X$-ray powder diffraction [35]. The results revealed that Si atoms occupy the body-centered positions, Fe and Co atoms occupy the body corners and form B2 and L $2{ }_{1}$ ordered phases. The L 21 phase is an ordered structure based on BCC with Pearson symbol of cF16. Just like Al, Si also tends to stabilize $\mathrm{BCC}$ structure. In the FeCoNi $(\mathrm{AlSi})_{0.4}$ alloy, although the fraction of $\mathrm{Al}$ element $(\mathrm{x}=0.4)$ is smaller as compared to the case in $\mathrm{Al}_{\mathrm{x}} \mathrm{CoCrFeNi}$ alloy ( $\mathrm{BCC}$ phase in $\mathrm{x} \geq 1.25$ ), there will be a large amount of $\mathrm{Ni}-\mathrm{Al}$ and Co-Si pairs first formed and other constituents will dissolve in the parent crystal structure due to the mixing entropy effect. Thus, the system forms a BCC structure.
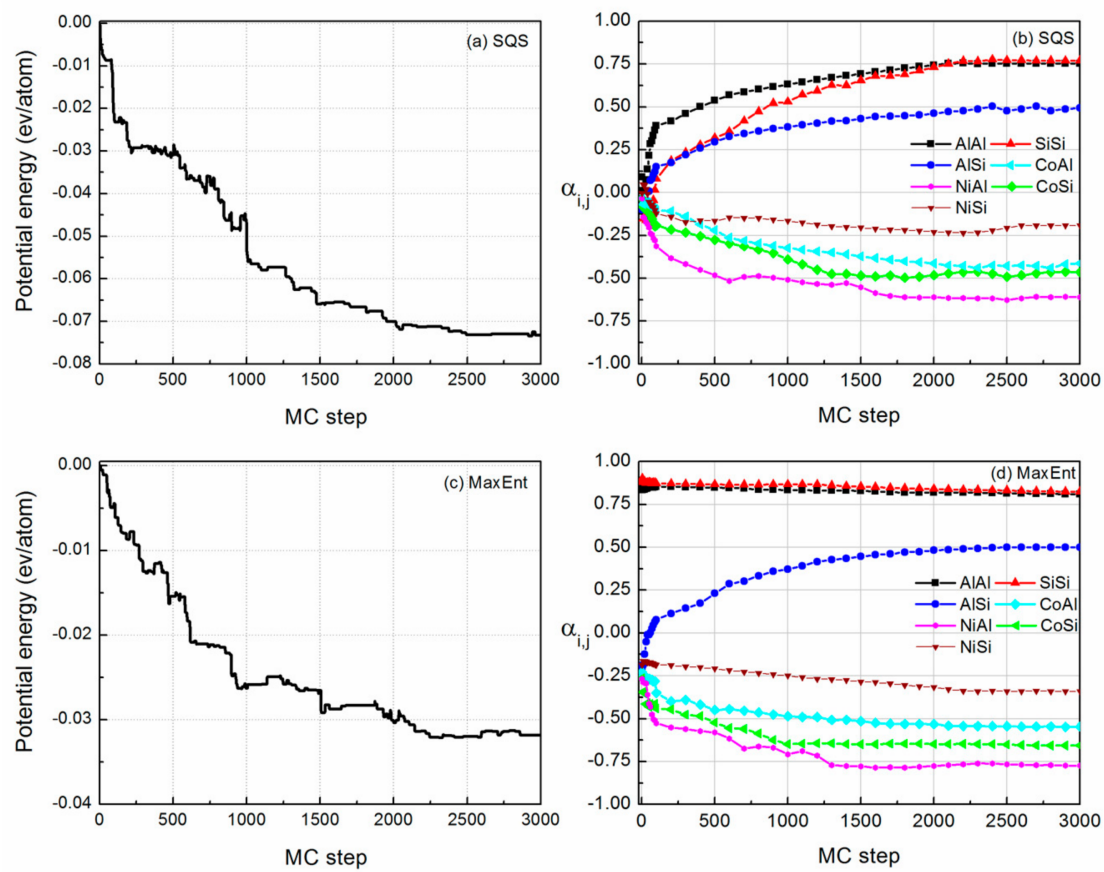

Figure 2. The evolution of relative potential energy and the corresponding short-range order (SRO) parameters of $\mathrm{FeCoNi}(\mathrm{AlSi})_{0.8}$ alloy: $(\mathbf{a}, \mathbf{b})$ with special quasi-random structures (SQS) structure; $(\mathbf{c}, \mathbf{d})$ with maximum entropy(MaxEnt) structure as the initial structure.

In the case where the MaxEnt structure is selected as the initial starting structure (Figure 2c,d), since each constituent atoms in the system strives for the maximum free space, $\alpha_{i i}=0.92$ and $\alpha_{i j}=-0.22$ for FeCoNi(AlSi) ${ }_{0.8}$ alloy. We obtained the lower potential energy at the $2200 \mathrm{MC}$ step. After $800 \mathrm{MC}$ steps searches, the MC method did not find the lower energy structure. The emergence of the SRO reduced the potential energy, which made the potential energy change from -325 to $-359 \mathrm{meV}$ per atom. In Figure $2 d$, the SRO parameters of $\alpha_{S i S i}$ and $\alpha_{A l A l}$ decrease slightly. $\alpha_{S i S i}$ changes from 0.92 to 0.86 , and $\alpha_{A l A l}$ changes from 0.92 to 0.84 . We started from two different initial starting points to probe the change of the atomic nearest neighbor environment in FeCoNi $(\mathrm{AlSi})_{0.8}$ alloy, and obtained a similar trend to the SRO. It can be concluded that the potential energy curve is relatively converged after $3000 \mathrm{MC}$ steps simulation. From the above comparison, it can be seen that in the process of 
searching for the SRO structure, using the MaxEnt model as the initial starting structure is more efficient. This is based on the following two points: on the one hand, the potential energy of the MaxEnt structure is lower than that of the SQS structure, which can be validated from the difference in formation energy listed in Table 1. On the other hand, the SRO parameters $\alpha_{i i}$ and $\alpha_{i j}$ of the MaxEnt structure are closer to the SRO parameters of the finial SRO structure. Therefore, in the following probing of SRO, and the calculation of the magnetic and mechanical properties, the MaxEnt structure is selected as the initial structure.

The partial pair distribution function can be used to describe the relative positional preferences of different constituent elements. The shape and position of the peaks provide detailed information about the atomic local environment [36]. We used pair PDF to show the SRO structure of the FeCoNi(AlSi $)_{0.2}$ alloy, and the corresponding data are plotted in Figure 3 . We observe that there is no obvious lattice distortion in the alloy. The average bond lengths of Co-Si and Ni-Si are $\mathrm{r} \sim 2.45 \AA$, which is shorter than the metal-metal bonds because the Si atom has a smaller radius than the metal atoms (Fe, Co, Ni, and $\mathrm{Al}$ ). The Ni-Al pair has a higher peak intensity, followed by the Co-Si and Fe-Co, Ni-Si pairs. The peaks of the Al-Al and Al-Si pairs have moved to the second nearest neighbor shell, and the peak of the Si-Si pair has moved to the third nearest neighbor shell, indicating that $\mathrm{Al}$ and Si prefer to bond with other elements rather than themselves. The results suggest the existence of the preferred Ni-Al, Co-Si, Fe-Co and Ni-Si pairs in the FeCoNi(AlSi) 0.2 alloy.
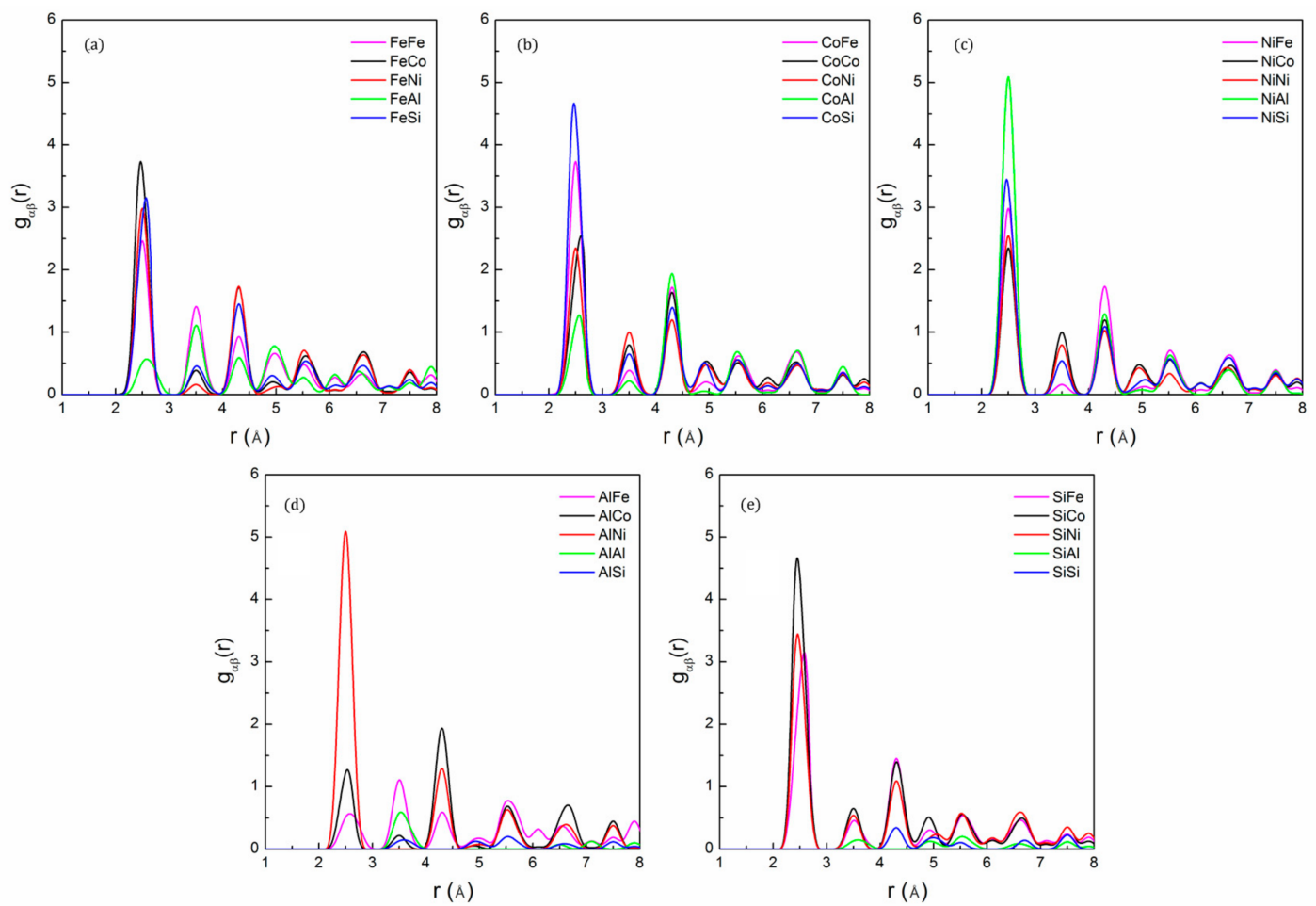

Figure 3. The partial pair distribution function for: (a) Fe; (b) $\mathrm{Co}$; (c) $\mathrm{Ni}$; (d) $\mathrm{Al}$ and (e) $\mathrm{Si}$ of FeCoNi(AlSi) $)_{0.2}$ alloy after the $3000 \mathrm{MC}$ step, showing short-range order between Ni-Al, Co-Si and Fe-Co pairs.

The partial PDF of the FeCoNi(AlSi) ${ }_{0.8}$ alloy after the $3000 \mathrm{MC}$ steps is shown in Figure 4 . It can be seen that the most preferred pair is Ni-Al, followed by the Co-Si, Co-Al, Fe-Si and Ni-Si pairs. The least favored pairs are the Si-Si, Al-Al pairs. Al and $\mathrm{Si}$ atoms prefer to bond with other elements to lower the potential energy. The results suggest the existence of a preferred short-range order of $\mathrm{Ni}-\mathrm{Al}, \mathrm{Co}-\mathrm{Si}, \mathrm{Co}-\mathrm{Al}, \mathrm{Fe}-\mathrm{Si}$ and Ni-Si pairs in the alloy. In addition, there is obvious lattice distortion when the fraction of $\mathrm{Al}$ and $\mathrm{Si}$ atoms is larger. The lattice distortion makes the second intensity peak smear out and become less distinct, indicating that the atoms in the alloy deviate from the ideal lattice 
positions. The lattice distortion can significantly scatter free electrons, shortened electrons mean free paths, which will reduce the thermal and electrical conductivity of the alloy.
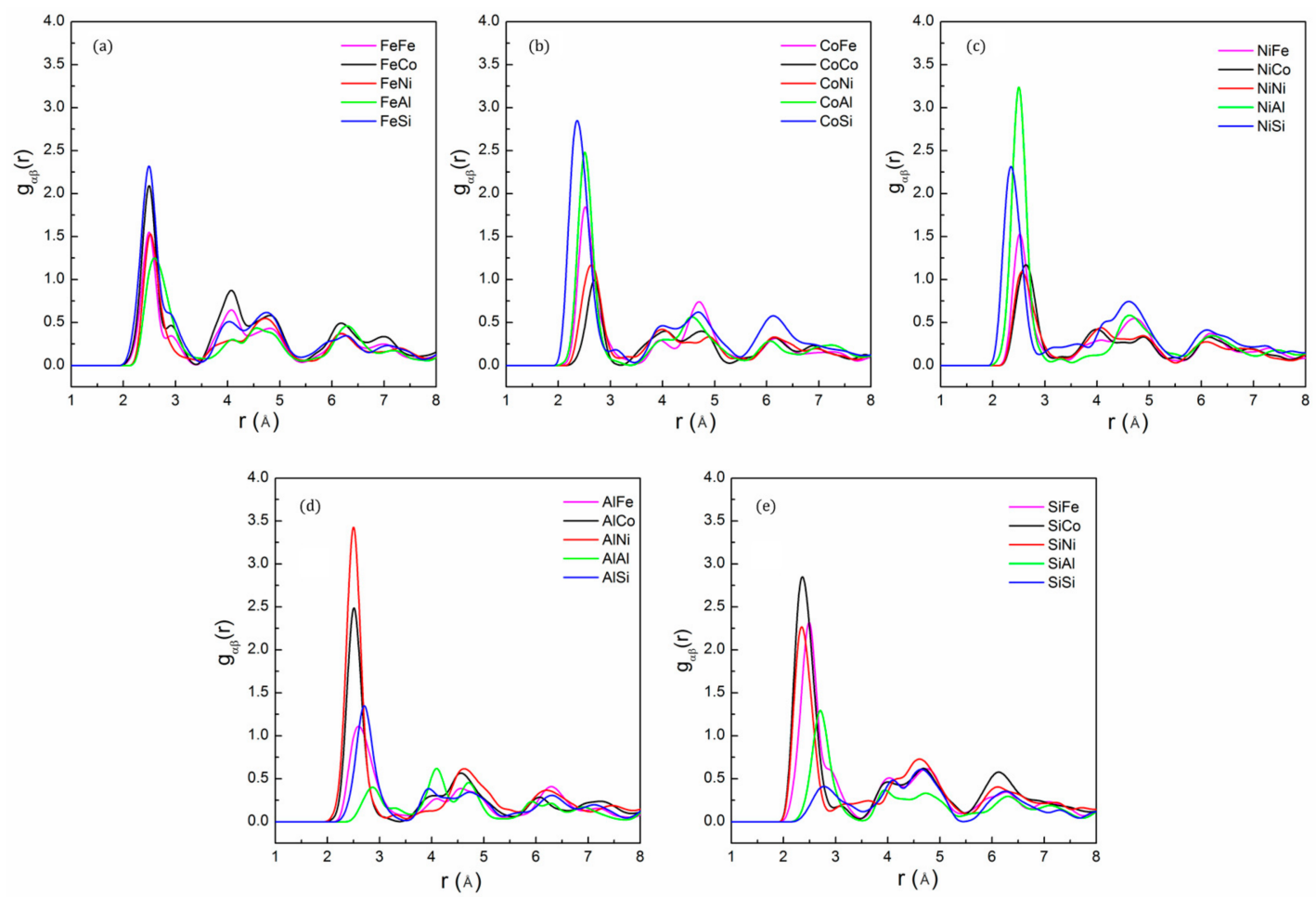

Figure 4. The partial pair distribution function: (a) Fe; (b) $\mathrm{Co}$; (c) $\mathrm{Ni}$; (d) $\mathrm{Al}$ and (e) $\mathrm{Si}$ of FeCoNi(AlSi) $)_{0.8}$ alloy after the $3000 \mathrm{MC}$ step, indicating short-range order between $\mathrm{Ni}-\mathrm{Al}, \mathrm{Co}-\mathrm{Si}, \mathrm{Co}-\mathrm{Al}$ and Fe-Si pairs.

In Table 2, the SRO parameters of the $\mathrm{FeCoNi}(\mathrm{AlSi})_{\mathrm{x}}$ alloys as a function of $\mathrm{Al}$ and $\mathrm{Si}$ fraction $\mathrm{x}$ averaged after $3000 \mathrm{MC}$ steps are shown. For FeCoNi alloy, we observed that the SRO parameter of the Fe-Ni pair is negative, and the $\mathrm{Fe}-\mathrm{Fe}, \mathrm{Ni}-\mathrm{Ni}$ and $\mathrm{Co}-\mathrm{Co}$ pairs are positive. Fe atoms prefer to bond with $\mathrm{Ni}$ atoms and form an SRO structure. Tamm et al. investigated the SRO behavior of $\mathrm{NiCrCoFe}$ alloys and found a negative $\mathrm{Ni}-\mathrm{Fe}$ pair and positive $\mathrm{Fe}-\mathrm{Fe}, \mathrm{Ni}-\mathrm{Ni}$ and $\mathrm{Co}-\mathrm{Co}$ pairs [16]. When $\mathrm{Al}$ and $\mathrm{Si}$ atoms are added to the FeCoNi-based alloy, the $\mathrm{Fe}-\mathrm{Ni}$ pair become positive. Al and Si elements have relative stronger attractive interaction with other constituent elements. They will separate from each other and bond with $\mathrm{Fe}, \mathrm{Co}$ and Ni elements to form an SRO structure. The strength of the attractive interaction can be seen from the binary mixing enthalpies [37], that is, the more negative the binary mixing enthalpy, the stronger the attractive interaction between the binary pair. This is applicable to other HEAs as well. The SRO depends on the type of constituent elements present in the HEAs. If a constituent element has a stronger attractive interaction with the other constituent elements, the atoms of this element will separate from each other and bond with other constituent elements to form an SRO structure. Also, the concentration of the constituent elements can change the degree of SRO. We observed that the SRO parameter of $\mathrm{Co}-\mathrm{Al}$ changes from $0.34(\mathrm{x}=0.2)$ to $-0.56(\mathrm{x}=0.8)$ and Co-Co changes from $0.15(x=0.2)$ to $0.84(x=0.8)$. It indicates that the element concentrations also have a certain influence on the degree of SRO. We think that a possibility for the formation of SRO in the HEAs is the enrichment of the preferred element pairs during solidification. At high temperature, the atomistic structure of liquid alloy is generally thought to be totally random due to the high mixing entropy effect. As the temperature decreases, the enthalpy effect becomes more important, and the non-random configuration shows a tendency toward phase separation or chemical short-range order, and some ordered phases may form during the solidification. Santodonato et al. studied the structural evolution of $\mathrm{Al}_{1.3} \mathrm{CoCrCuFeNi}$ alloy from the high temperature liquid phase to the room temperature phase [38]. The results demonstrated that the alloy is a liquid above $1315 \mathrm{~K}$ with $\mathrm{Al}-\mathrm{Ni}, \mathrm{Cr}-\mathrm{Fe}$ and 
$\mathrm{Cu}-\mathrm{Cu}$ the preferred nearest-neighbor pairs. The results demonstrated that the alloy is a liquid above $1315 \mathrm{~K}$ with $\mathrm{Al}-\mathrm{Ni}, \mathrm{Cr}-\mathrm{Fe}$ and $\mathrm{Cu}-\mathrm{Cu}$ preferred nearest-neighbor pairs. During the cooling of the melt, the ordered phases will be preserved.

Table 2. Short-range order (SRO) parameters of the FeCoNi ( $\mathrm{AlSi})_{\mathrm{x}}$ alloys as a function of $\mathrm{Al}$ and $\mathrm{Si}$ fraction $\mathrm{x}$.

\begin{tabular}{cccccccccc}
\hline Pair & $\mathbf{x = 0}$ & $\mathbf{x = 0 . 2}$ & $\mathbf{x = 0 . 4}$ & $\mathbf{x = 0 . 8}$ & Pair & $\mathbf{x = 0}$ & $\mathbf{x = 0 . 2}$ & $\mathbf{x}=\mathbf{0 . 4}$ & $\mathbf{x = 0 . 8}$ \\
\hline FeFe & 0.35 & 0.26 & -0.07 & -0.16 & CoSi & & -0.37 & -0.54 & -0.72 \\
FeCo & -0.04 & -0.34 & -0.24 & -0.08 & NiNi & 0.37 & -0.12 & -0.07 & 0.23 \\
FeNi & -0.31 & 0.04 & 0.30 & 0.23 & NiAl & & -1.04 & -0.84 & -0.78 \\
FeAl & & 0.32 & 0.30 & 0.36 & NiSi & & -0.31 & -0.28 & -0.19 \\
FeSi & & -0.28 & -0.32 & -0.37 & AlAl & & 1.00 & 0.95 & 0.84 \\
CoCo & 0.11 & 0.15 & 0.53 & 0.84 & $\mathrm{AlSi}$ & & 1.00 & 0.72 & 0.54 \\
CoNi & -0.06 & 0.19 & 0.22 & 0.45 & $\mathrm{SiSi}$ & & 1.00 & 0.96 & 0.86 \\
CoAl & & 0.34 & -0.38 & -0.56 & & & & & \\
\hline
\end{tabular}

Due to the preferred Ni-Al, Co-Al and Fe-Si pairs in the BCC phase of FeCoNi (AlSi $)_{0.4}$ and FeCoNi (AlSi) $)_{0.8}$ alloys, a B2-ordered phase structure may be formed. In the multi-component ordered BCC alloys, the crystal structure can be divided in two interpenetrating sublattices, designed by an $\alpha$ sublattice, and a $\beta$ sublattice. $x_{i \alpha}$ and $x_{i \beta}$ denote the molar fraction of the ith element on $\alpha$ and $\beta$ sublattices. The B2-ordered parameter $\eta_{i}$ was used to quantify the degree of ordering of the ith element in the sublattices [38]. $\eta_{i}$ is described using:

$$
\eta_{i}=\frac{x_{i \alpha}-x_{i \beta}}{x_{i \alpha}+x_{i \beta}}
$$

The total order parameter $\eta$ is calculated from $\eta_{i}$ with the equation:

$$
\eta=\sqrt{\sum_{i=1}^{n} x_{i} \eta_{i}^{2}}
$$

where $x_{i}$ is the overall molar fraction. $\eta=0$ indicates the random solid solution, and $\eta=1$ shows the fully B2-ordered structure.

The mixing entropy for the case of a B2 structure can be calculated:

$$
\Delta S_{\text {mix }}^{B 2}=-\frac{R}{2} \sum_{i=1}^{n}\left\{x_{i}\left(1+\eta_{i}\right) \operatorname{Ln}\left(x_{i}\left(1+\eta_{i}\right)\right)+x_{i}\left(1-\eta_{i}\right) \operatorname{Ln}\left(x_{i}\left(1-\eta_{i}\right)\right)\right\}
$$

In Table 3, we presented the ordering parameter $\eta_{i}, \eta$ and the mixing entropy for the ideal, and taking into account the B2-ordered structure. For the FeCoNi (AlSi) 0.4 alloy, $\eta_{A l}=0.692, \eta_{S i}=-0.231$ and $\eta_{N i}=-0.294$, indicating that $\mathrm{Al}$ prefers to occupy the $\alpha$ sublattice and $\mathrm{Ni}$ and Si prefer the $\beta$ sublattice to form the B2 phase. The total B2-ordered parameter was $\eta=0.294$ when $\mathrm{x}=0.8, \eta_{A l}=0.652, \eta_{C o}=-0.428$ and $\eta_{N i}=-0.481$, indicating that $\mathrm{Al}$ prefers to occupy the $\alpha$ sublattice and $\mathrm{Ni}$ and Co prefer the $\beta$ sublattice to form the B2 phase. With the increase of Al and Si content, the total B2-ordered parameter $\eta$ reaches 0.427 . The emergence of the $\mathrm{B} 2$ phase in the alloys reduces the configuration entropy from 1.521 to $1.475 \mathrm{R}$ for the FeCoNi (AlSi) 0.4 alloy, forming $1.606 \mathrm{R}$ to $1.509 \mathrm{R}$ for the FeCoNi(AlSi $)_{0.8}$ alloy.

Table 3. The order parameter $\eta_{\mathrm{i}}$, the mixing entropy for the ideal, taking into account the B2-ordered structure for $\mathrm{FeCoNi}(\mathrm{AlSi})_{0.4}$ and $\mathrm{FeCoNi}(\mathrm{AlSi})_{0.8}$ alloys.

\begin{tabular}{ccccccccc}
\hline Alloy & $\eta_{F e}$ & $\eta_{C o}$ & $\eta_{N i}$ & $\eta_{A l}$ & $\eta_{S i}$ & $\eta$ & $\Delta S_{\text {mix }}^{B 2}$ & $\Delta S_{\text {mix }}^{\text {ideal }}$ \\
\hline FeCoNi(AlSi) $)_{0.4}$ & 0.176 & -0.06 & -0.294 & 0.692 & -0.231 & 0.294 & 1.475 & 1.521 \\
FeCoNi(AlSi) $)_{0.8}$ & 0.259 & -0.428 & -0.481 & 0.652 & 0.130 & 0.427 & 1.509 & 1.606 \\
\hline
\end{tabular}




\subsection{SRO on Magnetic Properties}

As a reference, a series of calculations were carried out to determine the magnetic moments of Fe with BCC, Ni with FCC and Co with HEX structure, respectively. The calculated magnetic moments per $\mathrm{Fe}$, Co and $\mathrm{Ni}$ atom are $2.18 \mu_{\mathrm{B}}, 1.67 \mu_{\mathrm{B}}$, and $0.62 \mu_{\mathrm{B}}$, which are in good agreement with the experimental values [39]. The deviations between the calculated and the experimental lattice parameters (a) are within $1 \%$. Chandran et al. [40] investigated $\mathrm{Fe}_{1-\mathrm{x}} \mathrm{Co}_{\mathrm{x}}$ alloys in BCC structures and found that with the increase of Co contents, the magnetic moment per Fe atom increased from $2.22 \mu_{\mathrm{B}}(\mathrm{x}=0)$ to $2.76 \mu_{\mathrm{B}}(\mathrm{x}=0.5)$. Apiñaniz et al. [41] studied the magnetic properties of ordered $\mathrm{Fe}_{\mathrm{x}} \mathrm{Al}_{1-\mathrm{x}}$ alloys and found that the magnetic moment per Fe atom decreases from 2.22 to $0.64 \mu_{\mathrm{B}}$ with the increase in $\mathrm{Al}$ contents. The FeM, CoM and NiM binary ordered alloys $(\mathrm{M}=\mathrm{Fe}, \mathrm{Co}, \mathrm{Ni}, \mathrm{Al}$ and $\mathrm{Si}$ ) with BCC primitive cells were constructed. Taking the FeM alloy as an example, the Fe atom was assigned to the body-centered position and the $\mathrm{M}$ atom to the body corners. Table 4 listed the calculated magnetic moments per $\mathrm{Fe}, \mathrm{Co}$ and $\mathrm{Ni}$ atoms with the $\mathrm{M}$ atom in the nearest neighbor shell. It can be seen that $\mathrm{Co}$ and $\mathrm{Ni}$ atoms in the nearest neighbor shell of Fe atoms greatly increase the magnetic moment of $\mathrm{Fe}$ atoms, while $\mathrm{Al}$ and $\mathrm{Si}$ atoms in the nearest neighbor shell of magnetic atoms will drastically decrease the magnetic moments of magnetic atoms. Therefore, the atomic nearest neighbor environment has considerable influence on the atomic magnetic moments in alloys.

Table 4. The calculated magnetic moments of $\mathrm{Fe}, \mathrm{Co}$ and Ni in binary FeM-, CoM- and NiM-ordered alloys.

\begin{tabular}{cccccc}
\hline Element & Fe $\left(\mu_{B}\right)$ & Co $\left(\mu_{B}\right)$ & Ni $\left(\mu_{B}\right)$ & Al $\left(\mu_{B}\right)$ & Si $\left(\mu_{B}\right)$ \\
\hline $\mathrm{Fe}$ & 2.18 & 2.75 & 2.79 & 0.67 & 0 \\
$\mathrm{Co}$ & 1.69 & 1.62 & 1.60 & 0 & 0.53 \\
$\mathrm{Ni}$ & 0.69 & 0.63 & 0.61 & 0 & 0 \\
\hline
\end{tabular}

There is obvious $\mathrm{SRO}$ behavior in the FeCoNi $(\mathrm{AlSi})_{\mathrm{x}}$ alloys. The $\mathrm{SRO}$ will significantly change the atomic nearest neighbor environment, which has an impact on the magnetic properties of the alloys. The saturation magnetizations and average atomic magnetic moments of the $\mathrm{FeCoNi}(\mathrm{AlSi})_{\mathrm{x}}$ alloys with MaxEnt and SRO structures are summarized in Table 5. For the FeCoNi alloy, the average atomic magnetic moments per $\mathrm{Fe}, \mathrm{Co}$ and $\mathrm{Ni}$ atoms are 2.65, $1.64 \mu_{\mathrm{B}}$ and $0.62 \mu_{\mathrm{B}}$ with the initial structure. The $\mathrm{Co}$ and $\mathrm{Ni}$ atoms in the nearest neighbor of Fe atoms increase the magnetic moment of the Fe atoms. The effect of SRO on the magnetic moments of the FeCoNi alloy is relatively small. The calculated magnetic moments $\left(M_{S}=1.65 \mathrm{~T}\right)$ are consistent with the previous calculated values $\left(M_{S}=1.62 \mathrm{~T}\right)$ [22]. For the $\mathrm{FeCoNi}(\mathrm{AlSi})_{0.2}$ alloy, the SRO parameter of the Ni-Al pair reduces by $-100 \%$ and the nearest neighbor number of the $\mathrm{Ni}$ to $\mathrm{Al}$ atom changes from 3.5 to 7 for the SRO structure. Similarly, the SRO parameters of the $\mathrm{Co}-\mathrm{Si}, \mathrm{Ni}-\mathrm{Si}$ and $\mathrm{Fe}-\mathrm{Co}$ pairs are also negative. According to the atomic coordinate analysis, $\mathrm{Al}$ atoms occupy the body corners, while $\mathrm{Ni}$ atoms occupy the face-centered positions and form an $\mathrm{Ni}-\mathrm{Al}$ rich region. The negative SRO parameters of $\mathrm{Ni}-\mathrm{Al}, \mathrm{Ni}-\mathrm{Si}$ and $\mathrm{Fe}-\mathrm{Co}$ pairs present a similar trend with the experimental work [14] that the dendritic area is rich in Fe and Co atoms, while the inter-dendritic area is rich in $\mathrm{Al}, \mathrm{Ni}$, and $\mathrm{Si}$ atoms in FeCoNi (AlSi) $)_{0.2}$ alloy. In Figure 5, the average atomic magnetic moment $\mu_{i, j}$ of the $\mathrm{FeCoNi}(\mathrm{AlSi})_{0.2}$ and $\mathrm{FeCoNi}(\mathrm{AlSi})_{0.8}$ alloys are presented. $\mu_{i, j}$ is the average magnetic moment of the type $i$ element, which is calculated that there is type $j$ element in its nearest neighbor shell. The average magnetic moments $\mu_{F e, j}, \mu_{\mathrm{Co}, j}$ and $\mu_{N i, j}$ vary with different nearest neighbor elements. The results are different from the case of random solid solution. If each lattice is randomly occupied and the probability is proportional to the concentration of the element, the magnetic moment will be homogeneous. The SRO behavior decreases the atomic magnetic moments and the saturation magnetization of the system. The average magnetic moment of the Fe atom changes from 2.50 to $2.32 \mu_{\mathrm{B}}$, the Co atom from 1.43 to $1.19 \mu_{\mathrm{B}}$ and the Ni atom from 0.51 to $0.32 \mu_{\mathrm{B}}$. Compared to the previously-calculated saturation magnetization value $M_{s}=1.31 \mathrm{~T}$ 
with the random structure model [22], the saturation magnetization with $\mathrm{SRO}$ is $M_{S}=1.17 \mathrm{~T}$, which is closer to the experimental value $M_{S}=1.15 \mathrm{~T}$ [22].

Table 5. The saturation magnetizations $M_{s}$, the errors of calculated saturation magnetizations to experimental values and average magnetic moments $\left\langle\mu_{i}\right\rangle$ for FeCoNi(AlSi $)_{x}$ alloys with the MaxEnt structures and the finial structures with SRO, the calculated and experimental data from previous publications are also shown.

\begin{tabular}{|c|c|c|c|c|c|c|c|c|c|}
\hline Alloy & Ordering & Phase & $\begin{array}{l}M_{s} \\
(T)\end{array}$ & Error & $\begin{array}{c}\left\langle\mu_{F e}\right\rangle \\
\left(\mu_{B}\right)\end{array}$ & $\begin{array}{c}\left\langle\mu_{C o}\right\rangle \\
\left(\mu_{B}\right)\end{array}$ & $\begin{array}{c}\left\langle\mu_{N i}\right\rangle \\
\left(\mu_{B}\right)\end{array}$ & $\begin{array}{c}\left\langle\mu_{A l}\right\rangle \\
\left(\mu_{B}\right)\end{array}$ & $\begin{array}{c}\left\langle\mu_{S i}\right\rangle \\
\left(\mu_{B}\right)\end{array}$ \\
\hline FeCoNi & $\mathrm{RSM}^{1}$ & FCC & 1.62 & $22.73 \%$ & 2.65 & 1.66 & 0.62 & & - \\
\hline $\mathrm{FeCoNi}$ & MaxEnt & FCC & 1.63 & $23.48 \%$ & 2.65 & 1.64 & 0.62 & - & - \\
\hline $\mathrm{FeCoNi}$ & SRO & FCC & 1.65 & $25.00 \%$ & 2.67 & 1.63 & 0.63 & - & - \\
\hline $\mathrm{FeCoNi}$ & $\operatorname{Exp}^{2}$ & FCC & 1.32 & & & & & & \\
\hline $\mathrm{FeCoNi}(\mathrm{AlSi})_{0.2}$ & $\mathrm{RSM}^{1}$ & FCC & 1.31 & $13.91 \%$ & 2.48 & 1.50 & 0.52 & -0.05 & -0.06 \\
\hline $\mathrm{FeCoNi}(\mathrm{AlSi})_{0.2}$ & MaxEnt & FCC & 1.32 & $14.78 \%$ & 2.50 & 1.43 & 0.51 & -0.05 & -0.06 \\
\hline $\mathrm{FeCoNi}(\mathrm{AlSi})_{0.2}$ & SRO & FCC & 1.17 & $1.74 \%$ & 2.32 & 1.19 & 0.32 & -0.04 & -0.09 \\
\hline $\mathrm{FeCoNi}(\mathrm{AlSi})_{0.2}$ & $\operatorname{Exp}^{2}$ & FCC & 1.15 & & & & & & \\
\hline $\mathrm{FeCoNi}(\mathrm{AlSi})_{0.4}$ & MaxEnt & $\mathrm{BCC}$ & 1.14 & $21.28 \%$ & 2.48 & 1.39 & 0.35 & -0.03 & -0.04 \\
\hline $\mathrm{FeCoNi}(\mathrm{AlSi})_{0.4}$ & SRO & $\mathrm{BCC}$ & 1.06 & $12.77 \%$ & 2.43 & 1.25 & 0.26 & -0.03 & -0.04 \\
\hline $\mathrm{FeCoNi}(\mathrm{AlSi})_{0.4}$ & $\operatorname{Exp}^{2}$ & $\mathrm{BCC}$ & 0.94 & & & & & & \\
\hline $\mathrm{FeCoNi}(\mathrm{AlSi})_{0.8}$ & $\mathrm{RSM}^{1}$ & $\mathrm{BCC}$ & 0.67 & $45.65 \%$ & 2.08 & 0.88 & 0.21 & -0.02 & -0.03 \\
\hline $\mathrm{FeCoNi}(\mathrm{AlSi})_{0.8}$ & MaxEnt & $\mathrm{BCC}$ & 0.66 & $43.48 \%$ & 2.10 & 0.94 & 0.21 & -0.03 & -0.04 \\
\hline $\mathrm{FeCoNi}(\mathrm{AlSi})_{0.8}$ & $\mathrm{SRO}$ & $\mathrm{BCC}$ & 0.60 & $30.43 \%$ & 2.03 & 0.76 & 0.08 & -0.02 & -0.03 \\
\hline $\mathrm{FeCoNi}(\mathrm{AlSi})_{0.8}$ & $\operatorname{Exp}^{1}$ & $\mathrm{BCC}$ & 0.46 & error & & & & & \\
\hline
\end{tabular}

${ }^{1}$ Reference [22] (The calculated values with random structure model). ${ }^{2}$ Reference [22] (The experimental values).
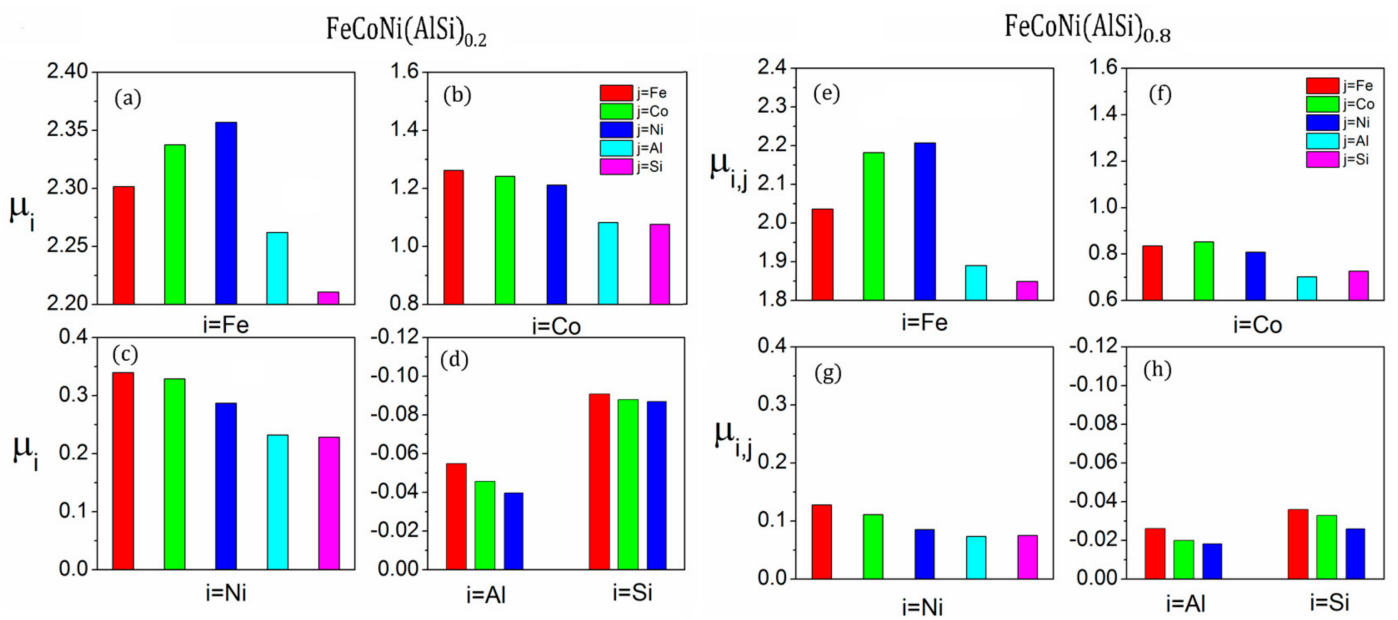

Figure 5. The average magnetic moments $\mu_{i, j}$ (unit in $\mu_{\mathrm{B}}$ ) with different nearest neighbor elements: (a-d) for FeCoNi (AlSi) 0.2 alloy; (e-h) for FeCoNi (AlSi) $)_{0.8}$ alloy.

The $\mathrm{FeCoNi}(\mathrm{AlSi})_{0.8}$ phase contains more $\mathrm{Al}$ and $\mathrm{Si}$ components. The $\mathrm{SRO}$ parameters of $\mathrm{Ni}-\mathrm{Al}$, $\mathrm{Co}-\mathrm{Si}, \mathrm{Co}-\mathrm{Al}, \mathrm{Fe}-\mathrm{Si}$ and $\mathrm{Ni}-\mathrm{Si}$ pairs are more negative. It is obvious that the $\mathrm{Fe}$, $\mathrm{Co}$ and $\mathrm{Ni}$ atoms prefer to gather around the $\mathrm{Si}$ atom, while the $\mathrm{Ni}$ and $\mathrm{Co}$ atoms prefer to gather around the $\mathrm{Al}$ atom. The SRO greatly alters the local environment of the magnetic atoms, which will further reduce the average magnetic moments of the magnetic atoms. The average magnetic moment of the Fe atoms changes from 2.10 to $2.03 \mu_{\mathrm{B}}$, Co atoms from 0.94 to $0.76 \mu_{\mathrm{B}}$. Due to the enrichment of $\mathrm{Al}$ and $\mathrm{Si}$ atoms in the nearest neighboring shell of $\mathrm{Ni}$ atoms, the magnetic moment of $\mathrm{Ni}$ atoms vanishes. The saturation magnetization changes from $0.67 \mathrm{~T}$ with the random structure to $0.6 \mathrm{~T}$ with the SRO structure. The saturation magnetization with $\mathrm{SRO}$ is closer to the experimental value $=0.46 \mathrm{~T}$ [22]. 


\subsection{SRO on Elastic Properties}

Mechanical properties are a vital aspect in material selection. It is important to understand the relationship of component, structure and mechanical properties for material applications. $\mathrm{FeCoNi}(\mathrm{AlSi})_{\mathrm{x}}$ alloys form $\mathrm{FCC}$ or $\mathrm{BCC}$ phase structures with different $\mathrm{Al}$ and $\mathrm{Si}$ fractions. There are three independent elastic constants $c_{11}, c_{12}$, and $c_{44}$ for the present cubic lattice. $c_{11}$ and $c_{12}$ can be determined from the bulk modulus $(B)$ and tetragonal shear modulus $\left(c^{\prime}\right)$ with $B=\left(c_{11}+2 c_{12}\right) / 3$, and $c^{\prime}=\left(c_{11}-c_{12}\right) / 2$. The bulk modulus can be obtained by fitting energy-volume data with the three-order Birch-Murnaghan equation of state [42]. Tetragonal shear modulus can be extracted from $\Delta E\left(\delta_{0}\right)=2 \mathrm{~V} \mathrm{c}^{\prime} \delta_{0}^{2}$ by applying orthorhombic strain $\left(\delta_{0}\right)$ to the cubic lattice. The elastic constant $\mathrm{c}_{44}$ can be obtained from fitting the energy-strain equation: $\Delta E\left(\delta_{m}\right)=2 \mathrm{Vc}_{44} \delta_{m}^{2}$ by applying the monoclinic strain $\left(\delta_{m}\right)$ to the base lattice [43]. The shear strain, strain matrix and energy-strain equations are shown in Table 6. In order to keep the elastic behavior of crystals, the applied strains should be relatively small, so the strains adopted are $\delta=-0.009,-0.006,-0.003,0,0.003,0.006,0.009$. The MaxEnt structure is a cubic lattice structure. We modified the basis vector matrix according to the strain matrix to apply different deformations to the supercell structures. The calculations of the total energy were conducted with $3 \times 3 \times 3 \mathrm{k}$-points to increase the accuracy. The energy curves of different deformations for the $\mathrm{FeCoNi}(\mathrm{AlSi})_{\times}$alloys are shown in Figure 6.

Table 6. The shear strain, strain matrix and the corresponding energy-strain equation to calculate $c_{11}$, and $\mathrm{c}_{44}$ for the cubic structure.

\begin{tabular}{cccc}
\hline Shear Strain & Strain Matrix & Energy-Strain Equation \\
\hline $\mathrm{e}=(\delta, \delta, \delta, 0,0,0)$ & {$\left[\begin{array}{ccc}1+\delta & 0 & 0 \\
0 & 1+\delta & 0 \\
0 & 0 & 1+\delta\end{array}\right]$} & $\frac{\Delta E}{V_{0}}=\frac{3}{2}\left(c_{11}+2 c_{12}\right) \delta^{2}$ \\
$\mathrm{e}=$ & {$\left[\begin{array}{ccc}1+\sigma & 0 & 0 \\
0 & 1-\sigma & 0 \\
0 & 0 & \frac{1}{1-\sigma^{2}}\end{array}\right]$} & $\frac{\Delta E}{V_{0}}=2 \mathrm{cl} \delta^{2}$ \\
$\left(0,-\delta, \frac{1}{1-\sigma^{2}}-1,0,0,0\right)$ & {$\left[\begin{array}{ccc}1 & \delta & 0 \\
\delta & 1 & 0 \\
0 & 0 & \frac{1}{1-\sigma^{2}}\end{array}\right]$} & $\frac{\Delta E}{V_{o}}=2 c_{44} \delta^{2}$ \\
\hline
\end{tabular}
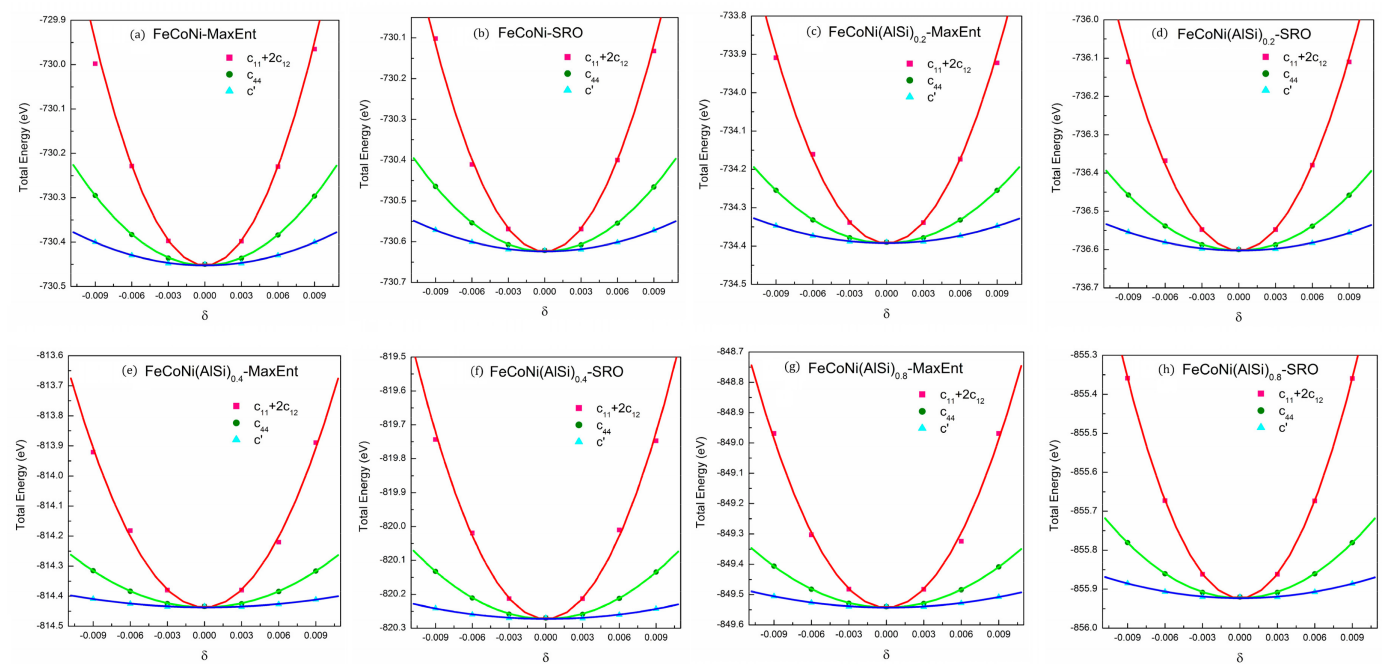

Figure 6. The total energies curves of different deformations for $c_{11}+2 c_{12}$. 
The shear modulus $G$ is calculated by the Hill average $G=\left(G_{V}+G_{R}\right) / 2$, and the Voigt and Reuss bounds shear modulus can be obtained by using Equations (6) and (7):

$$
\begin{gathered}
G_{V}=\left(c_{11}-c_{12}+3 c_{44}\right) / 5 \\
G_{R}=5\left(c_{11}-c_{12}\right) c_{44} /\left(4 c_{44}+3\left(c_{11}-c_{12}\right)\right)
\end{gathered}
$$

Young's modulus $(E)$ and Poisson's ratio $(v)$ are calculated from the bulk modulus $(B)$ and the shear modulus $(G)$ :

$$
\begin{gathered}
E=9 B G /(3 B+G) \\
v=(3 B-2 G) /[2(3 B+G)]
\end{gathered}
$$

The calculated lattice parameters, three elastic moduli $B, G, E$ and derived elastic moduli of the FeCoNi(AlSi $)_{x}$ alloys with the MaxEnt and SRO structures are presented in Table 7. From Table 7, all the calculated elastic constants $\left(c_{11}, c_{12}\right.$ and $\left.c_{44}\right)$ fulfill the mechanical stability criteria: $c_{44}>0, c_{11}>\left|c_{12}\right|$ and $\left(c_{11}+c_{12}\right)>0$, which demonstrates that the FeCoNi (AlSi) $)_{x}$ alloys are mechanically stable. The experimental information on the elastic modulus is very limited. The calculated lattice parameter for the FeCoNi alloy is $a=3.545 \AA$, and the experimental value is $3.599 \AA$ [22]. The calculated lattice parameter is closer to the value $a=3.563 \AA$ A calculated with EMTO [44]. The calculated bulk modulus is $B=184.7 \mathrm{GPa}$, shear modulus $G=84.5 \mathrm{GPa}$, and Young's modulus $E=219.8 \mathrm{GPa}$. The corresponding results calculated with EMTO are $B=186.1 \mathrm{GPa}, G=90.2 \mathrm{GPa}$ and $E=233.0 \mathrm{GPa}$.

\begin{tabular}{|c|c|c|c|c|c|c|c|c|c|c|c|c|c|}
\hline Alloy & Ordering & $a$ & $c_{11}$ & $c_{12}$ & $\mathrm{c}_{44}$ & $c_{12}-c_{44}$ & B & $G$ & $E$ & $v$ & $\mathrm{~B} / \mathrm{G}$ & $\mathrm{A}_{V R}$ & $\mathbf{A}_{Z}$ \\
\hline$X=0$ & MaxEnt & 3.545 & 243.6 & 155.3 & 130.2 & 25.1 & 184.7 & 84.5 & 219.8 & 0.302 & 2.19 & 0.13 & 2.94 \\
\hline$X=0$ & SRO & 3.543 & 244.8 & 156.6 & 131.9 & 24.7 & 186.0 & 85.1 & 221.5 & 0.302 & 2.19 & 0.14 & 2.99 \\
\hline$X=0.2$ & MaxEnt & 3.554 & 230.8 & 154.9 & 113.7 & 41.2 & 180.2 & 73.3 & 193.7 & 0.321 & 2.46 & 0.14 & 2.99 \\
\hline$X=0.2$ & SRO & 3.551 & 236.3 & 156.9 & 119.3 & 37.6 & 183.4 & 76.8 & 202.2 & 0.316 & 2.39 & 0.15 & 3.01 \\
\hline$X=0.4$ & MaxEnt & 2.836 & 201.7 & 150.2 & 92.9 & 57.3 & 167.4 & 55.8 & 150.5 & 0.350 & 3.00 & 0.17 & 3.61 \\
\hline$X=0.4$ & SRO & 2.831 & 207.1 & 153.3 & 98.1 & 52.2 & 171.2 & 58.6 & 157.9 & 0.346 & 2.92 & 0.18 & 3.65 \\
\hline$X=0.8$ & MaxEnt & 2.853 & 182.6 & 144.4 & 81.9 & 62.5 & 157.1 & 46.1 & 125.9 & 0.366 & 3.41 & 0.23 & 4.29 \\
\hline$X=0.8$ & SRO & 2.847 & 193.3 & 149.9 & 94.6 & 55.3 & 164.3 & 52.9 & 143.3 & 0.355 & 3.10 & 0.24 & 4.36 \\
\hline
\end{tabular}

Table 7. Calculated lattice parameters $a(\AA)$, elastic constants $\left(c_{11}\right.$ and $\left.c_{44}\right)$, bulk modulus $B$, shear modulus $G$, Young's modulus $E$, and derived elastic moduli of the FeCoNi(AlSi) $)_{x}$ alloys. The unit for the elastic moduli is GPa

The bulk modulus is a measure of the resistance to compressibility of a material. From the calculations, it can be seen that the fractions of $\mathrm{Al}$ and Si have significant influence on bulk modulus of $\mathrm{FeCoNi}(\mathrm{AlSi})_{\mathrm{x}}$ alloys. It is observed that the elastic constants $\left(\mathrm{c}_{11}, \mathrm{c}_{12}\right.$ and $\left.\mathrm{c}_{44}\right)$ and the three elastic moduli $(B, G$ and $E)$ decrease with increase of $\mathrm{Si}$ and $\mathrm{Al}$ fractions. The bulk modulus changes from 184.7 GPa $(\mathrm{x}=0)$ to $157.1 \mathrm{GPa}(\mathrm{x}=0.8)$. Note that $\mathrm{Al}$ and $\mathrm{Si}$ have a smaller bulk modulus compared to $\mathrm{Fe}, \mathrm{Co}$ and Ni components. Also the addition of $\mathrm{Al}$ and $\mathrm{Si}$ make the alloy structure change from the FCC to BCC phase (the packing factor changes from 0.74 to 0.68 ), which will result in a decrease of the bulk modulus. Taking into account the effect of SRO, SRO behavior prefers to make the affinity atoms locate together, resulting in an increase of the average bonding strength and a decrease of alloy volume. The FeCoNi(AlSi) $)_{x}$ alloys with SRO have a higher bulk modulus as compared to that of random solid structures. We also observed that SRO has similar effects on shear modulus and Young's modulus.

The Pugh's ratio $(B / G)[45]$ and Poisson's ratio $(v)[46]$ can be used to qualify the ductile properties of a material. It was reported that an alloy material is ductile when $B / G>1.75$ and $v>0.31$, otherwise it is brittle. For FeCoNi(AlSi $)_{x}$ alloys, the Cauchy pressure $\left(c_{12}-c_{44}\right)$, Pugh's ratio and Poisson's ratio increase with the increase of $\mathrm{Al}$ and Si fractions. The trends of Cauchy pressure, Pugh's ratio B / G and Poisson's ratio vindicate the addition of $\mathrm{Al}$ and $\mathrm{Si}$ to FeCoNi alloys improves the ductility of alloys. However, it is observed that the SRO behavior reduces the Pugh's ratio, 
Poisson's ratio and Cauchy pressure, showing that SRO results in a reduction in the ductility of the material. The Zener ratio $A_{z}$ and the ratio $A_{V R}$ are used to describe the isotropy property of FeCoNi (AlSi) $)_{\mathrm{x}}$ alloys. $A_{z}=2 c_{44} /\left(c_{11}-c_{12}\right)$, and $A_{V R}=\left(G_{V}-G_{R}\right) /\left(G_{V}+G_{R}\right)$. For an isotropic cubic material, $A_{z}=1$ and $A_{V R}=0$. The values of $A_{z}$ and $A_{V R}$ indicate the relative degree of the elastic anisotropy. For $\mathrm{FeCoNi}(\mathrm{AlSi})_{\mathrm{x}}$ alloys, the Zener ratio $A_{z}$ changes from 2.94 to 4.29 and $A_{V R}$ changes from 0.13 to 0.23 with the increase of $\mathrm{Al}$ and $\mathrm{Si}$ fractions. The $\mathrm{Al}$ and $\mathrm{Si}$ enhance the anisotropy of the $\mathrm{FeCoNi}(\mathrm{AlSi})_{\mathrm{x}}$ alloys. When taking into account the effect of $\mathrm{SRO}$, the $A_{z}$ changes from 2.99 to 4.36 and the $A_{V R}$ changes from 0.14 to 0.24 . The SRO behavior further enhances the anisotropy of the $\mathrm{FeCoNi}(\mathrm{AlSi})_{\mathrm{x}}$ alloys. From the above results, it can be seen that although $\mathrm{SRO}$ has a positive effect on $\mathrm{B}, \mathrm{G}$ and $\mathrm{E}$, it has a negative effect on the ductility and isotropic properties of the materials.

\section{Conclusions}

Using Monte Carlo simulation in combination with density functional theory, we investigated the SRO behavior of FeCoNi-based high entropy alloys. We took the SQS and MaxEnt structures as the initial starting point to probe the SRO structure in the system and found that using the MaxEnt structure as the initial starting point was more efficient. The calculated results show that there are obvious SRO structures in the $\mathrm{FeCoNi}(\mathrm{AlSi})_{\mathrm{x}}$ alloys. The binary mixing enthalpies between constituent elements were found to be the key factor in controlling the formation of SRO in a material. $\mathrm{Al}$ and $\mathrm{Si}$ elements have more negative binary mixing enthalpies with $\mathrm{Fe}, \mathrm{Co}$ and $\mathrm{Ni}$ elements. The average numbers of Al-Al, Al-Si and Si-Si pairs decrease significantly, while those of Ni-Al, Co-Si, Fe-Si, Ni-Si and Fe-Co pairs correspondingly increase. The changes in the $\mathrm{SRO}$ parameters indicate that $\mathrm{Al}$ and $\mathrm{Si}$ tend to bond with $\mathrm{Fe}, \mathrm{Co}$, and $\mathrm{Ni}$ atoms to lower the potential energy. The element concentrations also have a certain influence on the degree of SRO. The emergence of SRO will change the properties of high entropy alloys, such as reducing the formation energy, altering the equilibrium volume of the system and decreasing the average atomic magnetic moments. The SRO further reduces the saturation magnetization and damages the ductility and isotropy. The present work shows that SRO behavior has an important influence on the magnetic and mechanical properties of high entropy alloys.

Acknowledgments: This work was supported by the National Natural Science Foundation of China (No. 51471164), the National Key R\&D Program of China (No. 2016YFB0701302), and the CAS Frontier Science Research Project (No. QYZDJ-SSW-JSC015). The authors thank the computational support from the Informalization Construction Project of Chinese Academy of Sciences during the 11th Five-Year Plan Period (No. INFO-115-B01). The Special Program for Applied Research on Super Computation of the NSFC-Guangdong Joint Fund (the second phase) are also highly acknowledged. Some of the calculations in this study were done on the Tianhe-II high performance computer system in the National Supercomputer Center in Guangzhou, China.

Author Contributions: Shaoqing Wang conceived the modeling approach. Wenqiang Feng performed the calculations and wrote the paper; Yang Qi read and corrected the paper.

Conflicts of Interest: The authors declare no conflict of interest. The founding sponsors had no role in the design of the study; in the collection, analyses, or interpretation of data; in the writing of the manuscript, and in the decision to publish the results.

\section{References}

1. Yeh, J.W.; Lin, S.J.; Chin, T.S.; Gan, J.Y.; Chen, S.K.; Shun, T.T.; Tsau, C.H.; Chou, S.Y. Formation of simple crystal structures in Cu-Co-Ni-Cr-Al-Fe-Ti-V alloys with multiprincipal metallic elements. Metall. Mater. Trans. A 2004, 35, 2533-2536. [CrossRef]

2. Cantor, B.; Chang, I.T.H.; Knight, P.; Vincent, A.J.B. Microstructural development in equiatomic multicomponent alloys. Mater. Sci. Eng. A 2004, 375, 213-218. [CrossRef]

3. Tasan, C.C.; Deng, Y.; Pradeep, K.G.; Yao, M.J.; Springer, H.; Raabe, D. Composition Dependence of Phase Stability, Deformation Mechanisms, and Mechanical Properties of the CoCrFeMnNi High-Entropy Alloy System. JOM 2014, 66, 1993-2001. [CrossRef]

4. Gludovatz, B.; Hohenwarter, A.; Catoor, D.; Chang, E.H.; George, E.P.; Ritchie, R.O. A fracture-resistant high-entropy alloy for cryogenic applications. Science 2014, 345, 1153-1158. [CrossRef] [PubMed] 
5. Li, J.; Yang, X.; Zhu, R.; Zhang, Y. Corrosion and Serration Behaviors of $\mathrm{TiZr}_{0.5} \mathrm{NbCr}_{0.5} \mathrm{~V}_{\mathrm{x}} \mathrm{Mo}_{\mathrm{y}}$ High Entropy Alloys in Aqueous Environments. Metals 2014, 4, 597-608. [CrossRef]

6. Zuo, T.T.; Yang, X.; Liaw, P.K.; Zhang, Y. Influence of Bridgman solidification on microstructures and magnetic behaviors of a non-equiatomic FeCoNiAlSi high-entropy alloy. Intermetallics 2015, 67, 171-176. [CrossRef]

7. Wang, W.R.; Wang, W.L.; Wang, S.C.; Tsai, Y.C.; Lai, C.H.; Yeh, J.W. Effects of Al addition on the microstructure and mechanical property of $\mathrm{Al}_{x} \mathrm{CoCrFeNi}$ high-entropy alloys. Intermetallics 2012, 26, 44-51. [CrossRef]

8. Li, P.P.; Wang, A.; Liu, C.T. A ductile high entropy alloy with attractive magnetic properties. J. Alloy. Compd. 2017, 694, 55-60. [CrossRef]

9. Widom, M.; Huhn, W.P.; Maiti, S.; Steurer, W. Hybrid Monte Carlo/Molecular Dynamics Simulation of a Refractory Metal High Entropy Alloy. Metall. Mater. Trans. A 2013, 45, 196-200. [CrossRef]

10. Munoz, J.A.; Lucas, M.S.; Delaire, O.; Winterrose, M.L.; Mauger, L.; Li, C.W.; Sheets, A.O.; Stone, M.B.; Abernathy, D.L.; Xiao, Y.; et al. Positive vibrational entropy of chemical ordering in FeV. Phys. Rev. Lett. 2011, 107, 115501. [CrossRef] [PubMed]

11. Ghosh, T.; Jena, A.P.; Sanyal, B.; Sonomura, H.; Fukuda, T.; Kakeshita, T.; Mukhopadhyay, P.K.; Mookerjee, A. Effect of short range ordering on the magnetism in disordered Fe:Al alloy. J. Alloy. Compd. 2014, 613, 306-311. [CrossRef]

12. Jena, A.P.; Sanyal, B.; Mookerjee, A. Study of the effect of short ranged ordering on the magnetism in $\mathrm{FeCr}$ alloys. J. Magn. Magn. Mater. 2014, 349, 156-158. [CrossRef]

13. Manzoni, A.; Daoud, H.; Volkl, R.; Glatzel, U.; Wanderka, N. Phase separation in equiatomic AlCoCrFeNi high-entropy alloy. Ultramicroscopy 2013, 132, 212-215. [CrossRef] [PubMed]

14. Zuo, T.T.; Ren, S.B.; Liaw, P.K.; Zhang, Y. Processing effects on the magnetic and mechanical properties of $\mathrm{FeCoNiAl}_{0.2} \mathrm{Si}_{0.2}$ high entropy alloy. Int. J. Min. Met. Mater. 2013, 20, 549-555. [CrossRef]

15. Zhang, F.X.; Zhao, S.; Jin, K. Local Structure and Short-Range Order in a NiCoCr Solid Solution Alloy. Phys. Rev. Lett. 2017, 118, 205501. [CrossRef] [PubMed]

16. Tamm, A.; Aabloo, A.; Klintenberg, M.; Stocks, M.; Caro, A. Atomic-scale properties of Ni-based FCC ternary, and quaternary alloys. Acta Mater. 2015, 99, 307-312. [CrossRef]

17. Owen, L.R.; Playford, H.Y.; Stone, H.J.; Tucker, M.G. A new approach to the analysis of short-range order in alloys using total scattering. Acta Mater. 2016, 115, 155-166. [CrossRef]

18. McGreevy, R.L. Reverse Monte Carlo modelling. J. Phys. Condens. Matter. 2001, 13, R877-R913. [CrossRef]

19. Kaban, I.; Jóvári, P.; Stoica, M.; Eckert, J.; Hoyer, W.; Beuneu, B. Topological and chemical ordering in $\mathrm{Co}_{43} \mathrm{Fe}_{20} \mathrm{Ta}_{5.5} \mathrm{~B}_{31.5}$ metallic glass. Phys. Rev. B 2009, 79, 1377-1381. [CrossRef]

20. Hautier, G.; Jain, A.; Ong, S.P. From the computer to the laboratory: materials discovery and design using first-principles calculations. J. Mater. Sci. 2012, 47, 7317-7340. [CrossRef]

21. Kresse, G.; Furthmüller, J. Efficient iterative schemes for ab initio total-energy calculations using a plane-wave basis set. J. Phys. Condens. Matter. 1996, 54, 11169-11186.

22. Zhang, Y.; Zuo, T.T.; Cheng, Y.Q.; Liaw, P.K. High-entropy alloys with high saturation magnetization, electrical resistivity, and malleability. Sci. Rep. 2013, 3, 1455. [CrossRef] [PubMed]

23. Li, P.P.; Wang, A.; Liu, C.T. Composition dependence of structure, physical and mechanical properties of FeCoNi(MnAl $)_{X}$ high entropy alloys. Intermetallics 2017, 87, 21-26. [CrossRef]

24. Zhang, Q.; Xu, H.; Tan, X.H.; Hou, X.L.; Wu, S.W.; Tan, G.S.; Yu, L.Y. The effects of phase constitution on magnetic and mechanical properties of $\mathrm{FeCoNi}(\mathrm{CuAl})_{\mathrm{x}}(\mathrm{x}=0-1.2)$ high-entropy alloys. J. Alloy. Compd. 2017, 693, 1061-1067. [CrossRef]

25. Feng, W.Q.; Zheng, S.M.; Qi, Y.; Wang, S.Q. Periodic Maximum Entropy Random Structure Models for High-Entropy Alloys. Mater. Sci. Forum 2017, 898, 611-621. [CrossRef]

26. Wang, S.Q. Atomic Structure Modeling of Multi-Principal-Element Alloys by the Principle of Maximum Entropy. Entropy 2013, 15, 5536-5548. [CrossRef]

27. Wang, S.Q. Paracrystalline property of high-entropy alloys. AIP Adv. 2013, 3, 102105. [CrossRef]

28. Van de Walle, A.; Tiwary, P.; de Jong, M.; Olmsted, D.L.; Asta, M.; Dick, A.; Shin, D.; Wang, Y.; Chen, L.Q.; Liu, Z.K. Efficient stochastic generation of special quasirandom structures. Calphad 2013, 42, 13-18. [CrossRef]

29. Perdew, J.P.; Burke, K.; Ernzerhof, M. Generalized Gradient Approximation Made Simple. Phys. Rev. Lett. 1996, 77, 18-28. [CrossRef] [PubMed] 
30. Körmann, F.; Ma, D.; Belyea, D.D.; Lucas, M.S.; Miller, C.W.; Grabowski, B.; Sluiter, M.H.F. “Treasure maps” for magnetic high-entropy-alloys from theory and experiment. Appl. Phys. Lett. 2015, 107, 142404. [CrossRef]

31. Dobrzyński, L.; Wiśniewski, A.; Uemura, Y.J.; Shapiro, S.M.; Wicksted, J.P. Inelastic neutron scattering from sendust. Phys. Rev. B 1988, 37, 7175-7181. [CrossRef]

32. Hastings, W.K. Monte Carlo sampling methods using Markov chains and their applications. Biometrika 1970, 57, 97-109. [CrossRef]

33. Cowley, J.M. Short-Range Order and Long-Range Order Parameters. Phys. Rev. 1965, 138, A1384-A1389. [CrossRef]

34. Tsau, C.H.; Lin, S.X.; Fang, C.H. Microstructures and corrosion behaviors of FeCoNi and CrFeCoNi equimolar alloys. Mater. Chem. Phys. 2017, 186, 534-540. [CrossRef]

35. Raja, M.M.; Kamat, S.V. Structure, Magnetic, and Electrical Properties of Heusler-Type $\mathrm{Fe}_{3-\mathrm{x}} \mathrm{Co}_{\mathrm{x}} \mathrm{Si}$ Ferromagnetic Alloys. Metall. Mater. Trans. A 2015, 46, 4688-4697. [CrossRef]

36. Gao, M.; Alman, D. Searching for Next Single-Phase High-Entropy Alloy Compositions. Entropy 2013, 15, 4504-4519. [CrossRef]

37. Takeuchi, A.; Inoue, A. Classification of Bulk Metallic Glasses by Atomic Size Difference, Heat of Mixing and Period of Constituent Elements and Its Application to Characterization of the Main Alloying Element. Mater. Trans. 2005, 46, 2817-2829. [CrossRef]

38. Santodonato, L.J.; Zhang, Y.; Feygenson, M.; Parish, C.M.; Gao, M.C.; Weber, R.J.; Neuefeind, J.C.; Tang, Z.; Liaw, P.K. Deviation from high-entropy configurations in the atomic distributions of a multi-principal-element alloy. Nat. Commun. 2015, 6, 5964. [CrossRef] [PubMed]

39. Billas, I.M.; Chatelain, A.; de Heer, W.A. Magnetism from the atom to the bulk in iron, cobalt, and nickel clusters. Science 1994, 265, 1682-1684. [CrossRef] [PubMed]

40. Chandran, M.; Iorio, L.E.; Subramanian, P.R. Effect of nitrogen on the magnetic moment of $\alpha$-Fe and FeCo alloys from first-principle calculations. J. Appl. Phys. 2007, 101, 033912-033916. [CrossRef]

41. Apiñaniz, E.; Plazaola, F.; Garitaonandia, J.S. Influence of disorder on the magnetic properties of FeAl alloys: Theory. J. Non-Cryst. Solids 2001, 287, 302-307. [CrossRef]

42. Lejaeghere, K.; Speybroeck, V.V.; Oost, G.V.; Cottenier, S. Error Estimates for Solid-State Density Functional Theory Predictions: An Overview by Means of the Ground-State Elemental Crystals. Crit. Rev. Solid State 2014, 39, 1-24. [CrossRef]

43. Tian, F.Y.; Varga, L.K.; Chen, N.; Delczeg, L.; Vitos, L. Ab initio investigation of high-entropy alloys of 3d elements. Phys. Rev. B 2013, 87, 075144. [CrossRef]

44. Tian, F.Y.; Varga, L.K.; Shen, J.; Vitos, L. Calculating elastic constants in high-entropy alloys using the coherent potential approximation: Current issues and errors. Comp. Mater. Sci. 2016, 111, 350-358. [CrossRef]

45. Pugh, S.F. Relations between the elastic moduli and the plastic properties of polycrystalline pure metals. Philos. Mag. 2009, 45, 823-843. [CrossRef]

46. Gu, X.J.; McDermott, A.G.; Poon, S.J.; Shiflet, G.J. Critical Poisson's ratio for plasticity in FeMoCBLn bulk amorphous steel. Appl. Phys. Lett. 2006, 88, 211905. [CrossRef]

(c) 2017 by the authors. Licensee MDPI, Basel, Switzerland. This article is an open access article distributed under the terms and conditions of the Creative Commons Attribution (CC BY) license (http:/ / creativecommons.org/licenses/by/4.0/). 